\title{
Improved stability of blueberry juice anthocyanins by acidification and refrigeration
}

\author{
Luke R. Howard ${ }^{\mathrm{a}, *}$, Cindi Brownmiller ${ }^{\mathrm{a}}$, Andy Mauromoustakos ${ }^{\mathrm{b}}$ and Ronald L. Prior ${ }^{\mathrm{a}}$ \\ ${ }^{a}$ Department of Food Science, University of Arkansas, Fayetteville, Arkansas \\ ${ }^{\mathrm{b}}$ Agricultural Statistics Lab, 104 Agricultural Annex, University of Arkansas, Fayetteville, AR, USA
}

Received 20 December 2015; accepted 30 March 2016

\begin{abstract}
.
BACKGROUND: Blueberry anthocyanins are susceptible to degradation during juice processing and storage of juice at ambient temperature. Methods are needed to stabilize the health-promoting anthocyanins in blueberry and other anthocyaninrich berry juices.

OBJECTIVE: In this study we determined the effect of acidification ( $\mathrm{pH}$ 2.1, 2.5 and 2.9) of blueberry juice on changes in anthocyanins and percent polymeric color in response to juice processing and during eight months of storage at ambient and refrigerated temperatures.

METHODS: Three subsamples of non-pasteurized blueberry juice were adjusted to three $\mathrm{pH}$ levels: 2.9 (control, no $\mathrm{pH}$ adjustment), 2.5, and 2.1. After $\mathrm{pH}$ adjustment, juices were pasteurized and placed in storage at 4 and $25^{\circ} \mathrm{C}$. Samples were analyzed before (non-pasteurized) and after pasteurization, and after 2, 4, 6, and 8 months of storage at each temperature ( 4 and $25^{\circ} \mathrm{C}$ ) for anthocyanin composition by HPLC and percent polymeric color.

RESULTS: Blueberry juice acidified to $\mathrm{pH} 2.1$ retained higher levels of total anthocyanins and had lower percent polymeric color values than juice acidified to $\mathrm{pH} 2.5$ and control juice $(\mathrm{pH} 2.9)$ following pasteurization. Anthocyanin arabinosides were more susceptible to thermal degradation than glucosides, galactosides and acetylated derivatives. Levels of total anthocyanins declined markedly over 8 months of storage, but juices stored at $4^{\circ} \mathrm{C}$ had on average $56 \%$ higher levels of total anthocyanins than juices stored at $25^{\circ} \mathrm{C}$. Juice acidified to $\mathrm{pH} 2.1$ had on average $12 \%$ and $26 \%$ higher levels of total anthocyanins than $\mathrm{pH} 2.5$ and control juices, respectively. After 8 months of storage, juice acidified to $\mathrm{pH} 2.1$ had 11 and $22 \%$ higher levels of total anthocyanins than $\mathrm{pH} 2.5$ and control juices stored at $4{ }^{\circ} \mathrm{C}$, and $26 \%$ and $59 \%$ higher levels of total anthocyanins than $\mathrm{pH} 2.5$ and control juices stored at $25^{\circ} \mathrm{C}$. Acetylated derivatives were more prone to losses during storage than glycosides, especially in acidified juices.
\end{abstract}

CONCLUSIONS: Acidification of blueberry juice coupled with refrigerated storage are effective treatments to retain healthpromoting anthocyanins.

Keywords: Anthocyanins, blueberries, juice, processing, refrigeration, storage

\section{Abbreviations}

$\begin{array}{ll}\text { Ace } & \text { acetyl } \\ \text { Ara } & \text { arabinoside } \\ \text { Cyd } & \text { cyanidin }\end{array}$

\footnotetext{
*Corresponding author: Dr. Luke R. Howard, Department of Food Science, University of Arkansas, 2650N. Young Ave., Fayetteville, AR 72704, USA. Tel.: +1 479575 2978; Fax: +1 479575 6936; E-mail: lukeh@uark.edu.
} 


$\begin{array}{ll}\text { Dpd } & \text { delphinidin } \\ \text { Gal } & \text { galactoside } \\ \text { Glu } & \text { glucoside } \\ \text { Pnd } & \text { peonidin } \\ \text { Ptd } & \text { petunidin } \\ \text { Mvd } & \text { malvidin }\end{array}$

\section{Introduction}

Blueberries are a popular functional food due to their abundant levels of health-promoting polyphenols. The berries are exceptionally rich in anthocyanins, procyanidins and hydroxycinnamic acids and they also contain moderate levels of flavonols [1-3]. The high polyphenol content of the berries is responsible for the high free radical scavenging capacity measured in various in vitro assays [4-6]. In addition to protection against oxidative stress [7], the polyphenols in blueberries are known to exhibit a variety of biological properties including antiinflammation, anti-cancer, anti-heart disease and anti-aging protection $[8,9]$ and may play an important role in protection against a number of chronic diseases.

Fresh blueberries are susceptible to decay and have a limited shelf-life, hence they are commonly processed into various shelf-stable products including juices, jams, jellies, syrups, purees and berries canned in water or syrup. Unfortunately, processing has been shown to have a detrimental effect on blueberry polyphenols. Juice processing in particular has been shown to markedly reduce levels of blueberry anthocyanins [10-12] as a result of enzymatic degradation, physical removal of skins during pressing, and thermal treatments. In addition to losses during processing, anthocyanins readily decline during ambient temperature storage and are accompanied by increased polymeric color value values [12-14]. Several researchers have investigated ways to improve retention of anthocyanins during blueberry juice processing. Blanching blueberries prior to mashing has been shown to result in greater retention of anthocyanins due to inactivation of polyphenol oxidase [11, 15-17]. Other factors such as pasteurization time and temperature, oxygen, light and $\mathrm{pH}$ have also been shown to influence anthocyanin retention in blueberry juice $[18,19]$. Although the mechanism(s) responsible for anthocyanin losses during storage of blueberry juice are unknown, refrigeration has been shown to ameliorate losses [20, 21].

The stability and color of anthocyanins is strongly impacted by $\mathrm{pH}$. Under acidic conditions $\mathrm{pH}$ of 2 or less) anthocyanins exist in the flavylium cation form and possess a red or orange color, but as the $\mathrm{pH}$ increases above 3 hydration of the flavylium cation occurs giving rise to a colorless carbinol pseudo-base, which following ring opening is converted to the unstable chalcone pseudo-base [22]. Consistent with the scheme proposed by Brouillard [22] standard solutions of petanin and cyanidin 3-glucoside in $\mathrm{pH}$ 1.0, 2.4 and 3.1 buffers exhibited $90 \%$ or greater color stability over 60 days storage at $10^{\circ} \mathrm{C}$ [23]. Acidification of blueberry juice may be a viable treatment to prevent anthocyanin losses during processing and storage.

The objective of this study was to determine how acidification of blueberry juice (natural $\mathrm{pH}$ of 2.9 ) to $\mathrm{pH} 2.5$ and 2.1 impacts anthocyanin composition and percent polymeric color during processing and over eight months of storage at ambient and refrigerated temperatures.

\section{Materials and methods}

\subsection{Materials and juice processing}

Blueberries (cv. 'Bluecrop') harvested at the fully ripe stage were obtained from a commercial grower in Fayetteville, AR. The fruit were stored at $-20^{\circ} \mathrm{C}$ for less than two weeks prior to juice processing. Formic acid, 
citric acid, HPLC grade methanol, and potassium metabisulfite were obtained from Sigma Chemical Company (St. Louis, MO). A mixture of anthocyanin delphinidin, cyanidin, petunidin, peonidin, pelargonidin and malvidin glucosides was obtained from Polyphenols Laboratories AS (Sandnes, Norway).

Blueberries were processed into non-clarified juice using protocol previously described [12]. After measuring the $\mathrm{pH}$ of blueberry juice (2.9), we decided to acidify the other two treatments to $\mathrm{pH}$ values of 2.5 and 2.1 to determine if a high acid environment could afford protection against degradation of anthocyanins during pasteurization and juice storage. Three subsamples of juice were adjusted to three $\mathrm{pH}$ levels 2.9 (control, no $\mathrm{pH}$ adjustment), and 2.5, and 2.1 by drop-wise addition of a saturated (73\%) citric acid solution. After $\mathrm{pH}$ adjustment, the $\mathrm{pH} 2.5$ and 2.9 juices were adjusted with water to the same volume as the $\mathrm{pH} 2.1$ juice. Juices were filled into $170 \mathrm{~mL}$ glass bottles and pasteurized by heating in a steam box (American Sterilizer Co., Erie, Pa) until the juice temperature monitored using a thermocouple reached $90^{\circ} \mathrm{C}(\sim 90 \mathrm{sec})$. The bottle caps were then tightened and the juices were allowed to cool overnight. Samples of each juice treatment were stored in the dark at 4 and $25^{\circ} \mathrm{C}$. Samples ( 3 bottles/treatment) were analyzed before (non-pasteurized) and after pasteurization, and after $2,4,6$, and 8 months of storage at each temperature $\left(4\right.$ and $\left.25^{\circ} \mathrm{C}\right)$.

\subsection{HPLC-PDA and HPLC-MS analysis of anthocyanins}

Juice samples were passed through $0.45 \times$ um PTFE syringe filters (Varian, Inc., Palo Alto, CA) prior to HPLC analysis. The anthocyanins were separated on a $250 \times 4.6 \mathrm{~mm}$ Symmetry $\mathrm{C}_{18}{ }^{\circledR}$ column (Waters Corp., Milford, MA) using the conditions detailed in Cho et al. [2]. The mobile phase included a linear gradient of 5\% formic acid in water (A) and methanol (B) from $2 \% \mathrm{~B}$ to $60 \% \mathrm{~B}$ for $60 \mathrm{~min}$ at a flow rate of $1 \mathrm{~mL} / \mathrm{min}$. The anthocyanin peaks were monitored at $510 \mathrm{~nm}$ using a Waters Model 996 photodiode array detector. Individual cyanidin, delphinidin, peonidin, petunidin, and malvidin glycosides were quantified as corresponding equivalents of the five anthocyanin glucosides using external calibration curves of authentic standards ranging from 5 to $125 \mu \mathrm{g} / \mathrm{mL}$. Total anthocyanins were calculated as the sum of individual anthocyanin glycosides with results expressed as mg per $100 \mathrm{~mL}$ juice.

Anthocyanins were identified by HPLC-MS using identical conditions described above with the HPLC interfaced to a Bruker Esquire LC/MS ion trap spectrometer (Billerica, MA). Mass spectral analysis was conducted in positive ion electrospray mode using conditions previously described [2].

\subsection{Percent polymeric color analysis}

Percent polymeric color (PC) of juices was determined using the spectrophotometric assay of Giusti and Wrolstad [24]. Sample extracts were diluted with water in order to have an absorbance reading between 0.5 and 1.0 at $512 \mathrm{~nm}$ when evaluated by an 8452A Diode Array Spectrophotometer (Hewlett Packard, Palo Alto, CA). For analysis, $0.2 \mathrm{~mL}$ of $0.90 \mathrm{M}$ potassium metabisulfite was added to $2.8 \mathrm{~mL}$ diluted sample (bisulfite bleached sample) and $0.2 \mathrm{~mL}$ of DI water was added to $2.8 \mathrm{~mL}$ diluted sample (non-bleached, control sample). After equilibrating for $15 \mathrm{~min}$, but not more than $1 \mathrm{~h}$, samples were evaluated at $\lambda=700 \mathrm{~nm}, 512 \mathrm{~nm}$, and $420 \mathrm{~nm}$. Color density was calculated using the control sample according to the following formula:

$$
\text { Color Density }=\left[\left(\mathrm{A}_{420 \mathrm{~nm}}-\mathrm{A}_{700 \mathrm{~nm}}\right)+\left(\mathrm{A}_{512 \mathrm{~nm}}-\mathrm{A}_{700 \mathrm{~nm}}\right)\right] \times \text { Dilution Factor }
$$

Polymeric color was determined using the bisulfite-bleached sample using the following formula:

$$
\text { Polymeric Color }=\left[\left(\mathrm{A}_{420 \mathrm{~nm}}-\mathrm{A}_{700 \mathrm{~nm}}\right)+\left(\mathrm{A}_{512 \mathrm{~nm}}-\mathrm{A}_{700 \mathrm{~nm}}\right)\right] \times \text { Dilution Factor }
$$

Percent polymeric color was calculated using the formula:

$\%$ Polymeric color $=($ polymeric color/color density $) \times 100$ 


\subsection{Statistical analysis}

All statistical analysis was performed in the fit model platform of JMP (JMP Pro version 12.1.0, SAS Institute, Cary, NC). The statistical model for all responses for the pasteurization data set involved $3 \mathrm{pH}$ levels $(2.1,2.5$ and 2.9), non-pasteurized and pasteurized in a $3 \times 2$ design with three replications for each of the six treatment combinations. The statistical model for all responses for the storage study involved a $3 \times 4 \times 2$ factorial design with three $\mathrm{pH}$ levels, 4 storage times $(2,4,6$, and 8 months $)$, and 2 storage temperatures $\left(4\right.$ and $\left.25^{\circ} \mathrm{C}\right)$ also with three replications for each of the 24 treatment combinations. Tukey's HSD multiple comparisons were utilized to report mean differences among interactions simple and main effects were appropriate using $\alpha=0.05$ significance level in all cases.

\section{Results and discussion}

\subsection{Anthocyanin composition of blueberry juice}

A typical HPLC chromatogram of non-pasteurized juice produced from 'Bluecrop' blueberries is shown in Fig. 1. Seventeen peaks were identified by HPLC/MS: peak 1, delphinidin 3-O-galactoside $(\mathrm{m} / \mathrm{z}, 465 / 303)$; peak 2, delphinidin 3-O-glucoside $(\mathrm{m} / \mathrm{z} 465 / 303)$; peak 3, cyanidin 3-O-galactoside $(\mathrm{m} / \mathrm{z}, 449 / 287)$; peak 4, delphinidin 3-O-arabinoside $(\mathrm{m} / \mathrm{z} 435 / 303)$; peak 5, cyanidin 3-O-glucoside $(\mathrm{m} / \mathrm{z} 449 / 287)$; peak 6, petunidin 3-O-galactoside $(\mathrm{m} / \mathrm{z} 479 / 317)$; peak 7, cyanidin 3-O-arabinoside $(\mathrm{m} / \mathrm{z} 419 / 287)$; peak 8, petunidin 3-O-glucoside

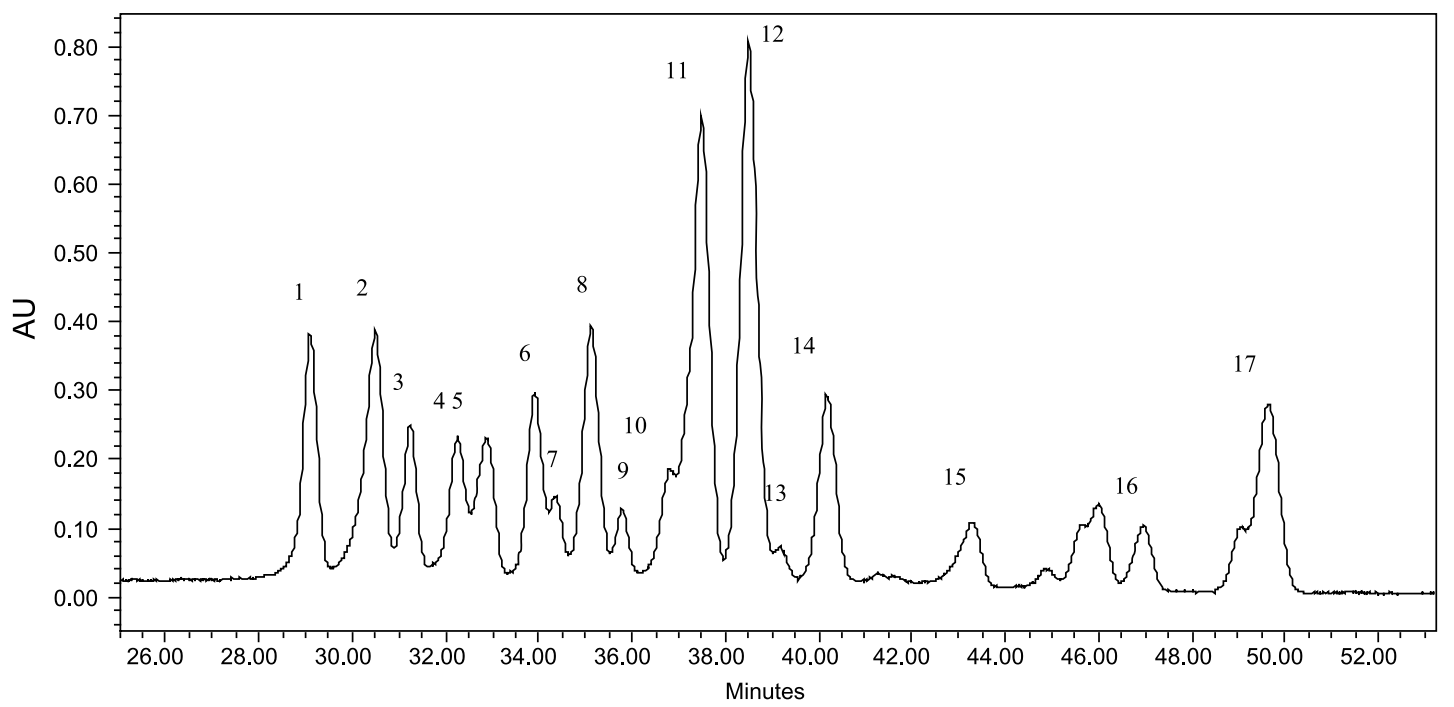

Fig. 1. Typical HPLC chromatogram (Abs $520 \mathrm{~nm}$ ) of blueberry juice anthocyanins. peak 1, delphinidin 3-O-galactoside $(\mathrm{m} / \mathrm{z} 465 / 303)$; peak 2, delphinidin 3-O-glucoside $(\mathrm{m} / \mathrm{z}, 465 / 303)$; peak 3, cyanidin 3-O-galactoside $(\mathrm{m} / \mathrm{z}$ 449/287); peak 4, delphinidin 3-O-arabinoside $(\mathrm{m} / \mathrm{z}$ 435/303); peak 5, cyanidin 3- $O$-glucoside $(\mathrm{m} / \mathrm{z}$ 449/287); peak 6, petunidin 3- $O$-galactoside $(\mathrm{m} / \mathrm{z}, 479 / 317)$; peak 7, cyanidin 3- $O$-arabinoside $(\mathrm{m} / \mathrm{z}$ 419/287); peak 8, petunidin 3-O-glucoside $(\mathrm{m} / \mathrm{z}$ 479/317); peak 9, peonidin 3-O-galactoside $(\mathrm{m} / \mathrm{z}, 463 / 301)$; peak 10, petunidin 3-Oarabinoside $(\mathrm{m} / \mathrm{z}$ 449/317); peak 11, malvidin 3-O-galactoside $(\mathrm{m} / \mathrm{z} 493 / 331)$; peak 12, malvidin 3-O-glucoside $(\mathrm{m} / \mathrm{z}$ 493/331); peak 13, peonidin 3-O-arabinoside (m/z 433/301); peak 14, malvidin 3-O-arabinoside ( $\mathrm{m} / \mathrm{z} 463 / 331)$; peak 15, delphinidin 3-O-(6"-acetylglucoside) $(\mathrm{m} / \mathrm{z}$ 507/303); peak 16, petunidin 3-O-(6"-acetylglucoside) $(\mathrm{m} / \mathrm{z} 521 / 317)$; peak 17, malvidin 3-O-(6"-acetylglucoside) $(\mathrm{m} / \mathrm{z} 535 / 331)$. 
( $\mathrm{m} / \mathrm{z}$ 479/317); peak 9, peonidin 3-O-galactoside $(\mathrm{m} / \mathrm{z} 463 / 301)$; peak 10, petunidin 3-O-arabinoside $(\mathrm{m} / \mathrm{z}$ 449/317); peak 11, malvidin 3-O-galactoside ( $\mathrm{m} / \mathrm{z} 493 / 331)$; peak 12 , malvidin 3- $O$-glucoside $(\mathrm{m} / z$ 493/331); peak 13, peonidin 3- $O$-arabinoside ( $\mathrm{m} / \mathrm{z} 433 / 301)$; peak 14 , malvidin 3- $O$-arabinoside $(\mathrm{m} / \mathrm{z} 463 / 331)$; peak 15 , delphinidin 3-O-(6"-acetylglucoside) $(\mathrm{m} / \mathrm{z}$ 507/303); peak 16, petunidin 3- $O$-(6"-acetylglucoside) $(\mathrm{m} / \mathrm{z}, 521 / 317)$; peak 17, malvidin 3-O-(6"-acetylglucoside) ( $/ 2 / z$ 535/331). Monomeric anthocyanins Mvd (41.2\%), Dpd (27.1\%), Ptd (18.3\%), Cyd (3.4\%) and Pnd (1.1\%) accounted for $91.1 \%$ of the total anthocyanins present in the nonpasteurized juice, while acetylated anthocyanins accounted for $8.9 \%$. These values are consistent with previous percentage distribution values reported for 'Bluecrop' blueberries, Dpd (26-41\%), Cyd (6-11\%), Ptd (17-21\%), Pnd (1-2\%) and Mvd (32-44\%) [2, 10, 25]. The percentage distribution of glycosides followed the order of Gal (39\%), Glu (33\%) and Ara (28\%), which agrees well with previous values Gal (39\%), Glu (31\%) and Ara (30\%) reported for 'Bluecrop' blueberries [2].

\section{2. pH effect on anthocyanins and percent polymeric color of non-pasteurized and pasteurized blueberry juice}

The effect of $\mathrm{pH}$ on total anthocyanin content and percent polymeric color of non-pasteurized and pasteurized blueberry juice is shown in Fig. 2, and the $\mathrm{pH}$ effect on individual anthocyanins is presented in Table 1. Acidifying the non-pasteurized juice from the natural blueberry $\mathrm{pH}$ of 2.9 to 2.5 and 2.1 had little to no effect on total anthocyanins and percent polymeric color. The pasteurization step resulted in 14, 21 and $20 \%$ losses of total anthocyanins in $\mathrm{pH} 2.1,2.5$, and 2.9 juices, respectively. The $\mathrm{pH} 2.1$ juices had a lower \% polymeric color value (11.7) than $\mathrm{pH} 2.5$ (14.7) and $\mathrm{pH} 2.9$ (14.3) juices following pasteurization, which is consistent with greater retention of monomeric anthocyanins in juices acidified to $\mathrm{pH}$ 2.1. Several studies have demonstrated that acidification improves anthocyanin and color stability in model solutions [23, 26, 27]. Additionally, acidification of blueberry juice to $\mathrm{pH} 1$ was shown to improve anthocyanin stability and prevent the increase of percent polymeric color values observed in juices adjusted to $\mathrm{pH} 4$ and 7 [19]. Improved stability of anthocyanins in

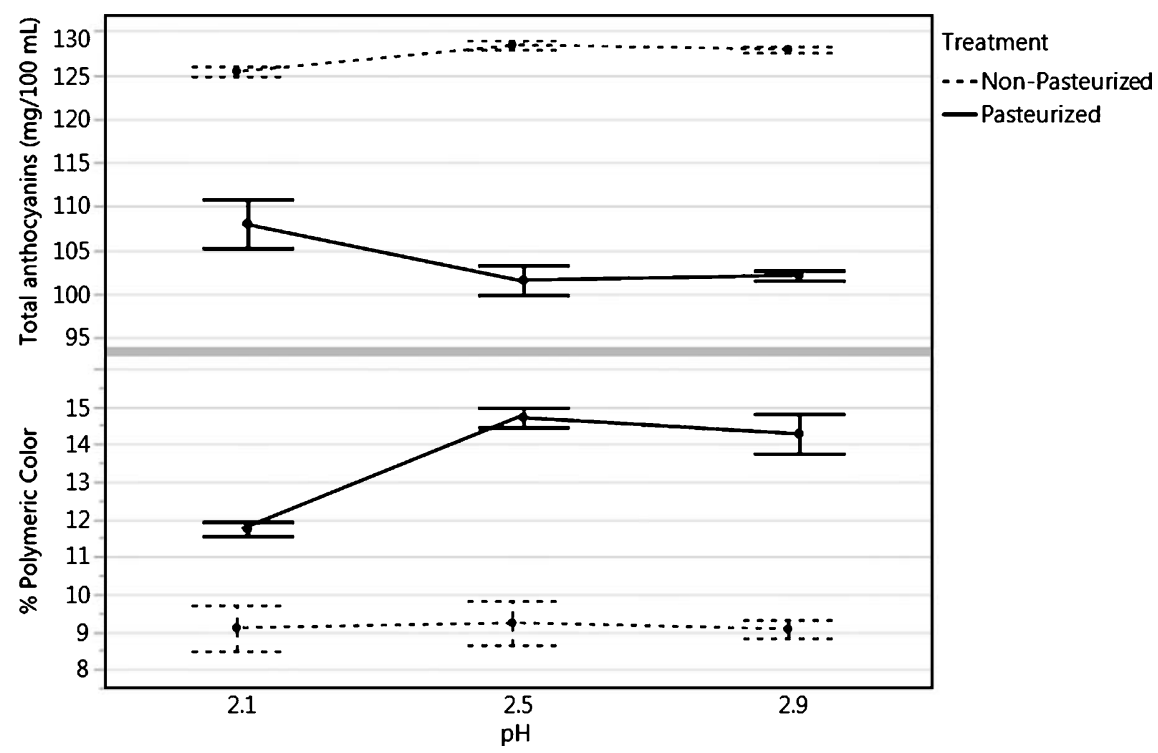

Fig. 2. Total anthocyanin content $(\mathrm{mg} / 100 \mathrm{~mL})$ and percent polymeric color of blueberry juice before and after pasteurization as affected by $\mathrm{pH}$. Bars represent standard error of the mean $(n=3)$. 
Table 1

Anthocyanin composition $(\mathrm{mg} / 100 \mathrm{~mL})$ of blueberry juice before and after pasteurization as affected by $\mathrm{pH}$

\begin{tabular}{|c|c|c|c|c|c|c|}
\hline \multirow[b]{2}{*}{ Anthocyanin } & \multicolumn{3}{|c|}{ Non-pasteurized } & \multicolumn{3}{|c|}{ Pasteurized } \\
\hline & $\mathrm{pH} 2.1$ & $\mathrm{pH} 2.5$ & $\mathrm{pH} 2.9$ & $\mathrm{pH} 2.1$ & $\mathrm{pH} 2.5$ & pH 2.9 \\
\hline Dpd 3-galactoside & $12.7 b c^{1}$ & $13.6 \mathrm{a}$ & $13.1 \mathrm{ab}$ & $11.9(94)^{2} \mathrm{~cd}$ & $11.2(82) \mathrm{e}$ & $11.3(86) \mathrm{de}$ \\
\hline Dpd 3-glucoside & $9.5 \mathrm{a}$ & $9.6 \mathrm{a}$ & $9.7 \mathrm{a}$ & $8.6(91) \mathrm{b}$ & $8.0(84) \mathrm{c}$ & $7.9(82) \mathrm{c}$ \\
\hline Dpd 3-arabinoside & $11.6 \mathrm{a}$ & $11.8 \mathrm{a}$ & $11.9 \mathrm{a}$ & $9.0(78) \mathrm{b}$ & $8.4(71) \mathrm{c}$ & $8.5(71) c$ \\
\hline Dpd 3-acetyl-glucoside & $3.7 \mathrm{a}$ & $3.8 \mathrm{a}$ & $3.8 \mathrm{ab}$ & $3.2(86) b$ & $3.1(81) b$ & $2.8(74) \mathrm{b}$ \\
\hline Cyd 3-galactoside & $1.3 \mathrm{bc}$ & $1.4 \mathrm{a}$ & $1.4 \mathrm{a}$ & $1.4(108) \mathrm{a}$ & $1.3(95) \mathrm{ab}$ & $1.2(88) \mathrm{c}$ \\
\hline Cyd 3-glucoside & $1.5 b$ & $1.6 \mathrm{~b}$ & $1.6 \mathrm{~b}$ & $1.7 \mathrm{a}(113)$ & $1.6(102) b$ & $1.6(100) \mathrm{a}$ \\
\hline Cyd 3-arabinoside & $1.4 \mathrm{a}$ & $1.4 \mathrm{a}$ & $1.5 \mathrm{a}$ & $1.2(84) b$ & $1.2(85) \mathrm{b}$ & $1.1(75) b$ \\
\hline Ptd 3-galactoside & $8.2 \mathrm{~b}$ & $8.6 \mathrm{a}$ & $8.4 \mathrm{ab}$ & $7.3(89) \mathrm{c}$ & $6.8(79) \mathrm{d}$ & $6.9(83) \mathrm{d}$ \\
\hline Ptd 3-glucoside & $8.7 \mathrm{a}$ & $8.8 \mathrm{a}$ & $8.8 \mathrm{a}$ & $7.7(89) b$ & $7.2(82) \mathrm{c}$ & $7.2(82) \mathrm{c}$ \\
\hline Ptd 3-arabinoside & $6.2 \mathrm{a}$ & $6.2 \mathrm{a}$ & $6.2 \mathrm{a}$ & $4.7(76) \mathrm{b}$ & $4.3(69) \mathrm{c}$ & $4.5(69) \mathrm{bc}$ \\
\hline Ptd 3-acetyl-glucoside & $2.3 \mathrm{a}$ & $2.3 \mathrm{a}$ & $2.3 \mathrm{a}$ & $2.1(93) \mathrm{b}$ & $2.1(88) b$ & $2.0(87) \mathrm{b}$ \\
\hline Pnd 3-galactoside & $1.3 \mathrm{a}$ & $1.4 \mathrm{a}$ & $1.4 \mathrm{a}$ & $1.4(108) \mathrm{a}$ & $1.3(97) \mathrm{a}$ & $1.3(93) \mathrm{a}$ \\
\hline Mvd 3-galactoside & $20.6 \mathrm{a}$ & $21.0 \mathrm{a}$ & $21.0 \mathrm{a}$ & $17.3(83) b$ & $16.2(77) \mathrm{c}$ & $16.4(78) c$ \\
\hline Mvd 3-glucoside & $18.4 \mathrm{a}$ & $18.6 \mathrm{a}$ & $18.5 \mathrm{a}$ & $16.3(89) b$ & $15.2(82) \mathrm{c}$ & $15.2(82) \mathrm{c}$ \\
\hline Mvd 3-arabinoside & $12.9 \mathrm{a}$ & $13.1 \mathrm{a}$ & $13.1 \mathrm{a}$ & $10.0(78) b$ & $9.3(71) \mathrm{c}$ & $9.5(71) \mathrm{c}$ \\
\hline Mvd 3-acetyl-glucoside & $5.1 b$ & $5.3 \mathrm{a}$ & $5.2 \mathrm{ab}$ & $4.1(80) \mathrm{e}$ & $4.4(83) \mathrm{d}$ & $4.6(88) c$ \\
\hline Total anthocyanins & $125.4 \mathrm{a}$ & $128.4 \mathrm{a}$ & $127.9 \mathrm{a}$ & $108.0(86) \mathrm{b}$ & $101.6(79) \mathrm{c}$ & $102.1(80) \mathrm{c}$ \\
\hline
\end{tabular}

${ }^{1}$ Mean values $(n=3)$ within rows with similar letters are not significantly different $(P>0.05) .{ }^{2}$ Values in parentheses for pasteurized values represent percent retention compared with corresponding non-pasteurized treatments.

blueberry juice at 2.1 following pasteurization as opposed to $\mathrm{pH} 2.5$ and 2.9 juices is due to shift of the anthocyanin structure to the flavylium cationic form, which confers a red color, whereas at $\mathrm{pH} 2.5$ and 2.9 the quinoidal blue species predominate [22].

All individual anthocyanins declined following pasteurization with the exception of Cyd 3-gal, Cyd 3-glu, and Pnd 3-gal, which were present in low amounts (Table 1). Following pasteurization, the $\mathrm{pH} 2.1$ juices had higher levels of Dpd 3-glu, Cyd 3-gal, Ptd 3-glu, Mvd 3-gal and Mvd 3-glu than pH 2.9 juices, and pH 2.1 juices also contained higher levels of Ptd 3-gal, Ptd 3-glu, Mvd 3-gal, Mvd 3-glu, and Mvd 3-ara than pH 2.5 juices. However, $\mathrm{pH} 2.1$ juices had lower levels of Mvd 3-ace-glu than $\mathrm{pH} 2.5$ and 2.9 juices. Degradation of anthocyanins appeared to be minimally affected by anthocyanidin structure. Percent retention of anthocyanidins after pasteurization were Pnd (100\%), Cyd (93\%), Dpd (82\%), Ptd (82\%) and Mvd (80\%), which agrees reasonably well with the retention order of $\mathrm{Cyd}>\mathrm{Pnd}>\mathrm{Ptd}>\mathrm{Dpd}>\mathrm{Mvd}$ for anthocyanidins in blueberry-Aronia nectar [28]. In contrast, Skrede et al. [10] reported that the order of anthocyanin stability in response to pasteurization of blueberry juice was Pnd $=\mathrm{Mvd}>\mathrm{Cyd}=\mathrm{Ptd}>\mathrm{Dpd}$. Excluding the two anthocyanins (Cyd and Pnd) which were present in minor amounts, retentions of the three major anthocyanidins, Dpd, Ptd and Mvd were similar (80-82\%), suggesting that anthocyanidin structure does not play a major role in stability of anthocyanins in response to thermal degradation confirming results of West and Mauer [27].

In terms of sugar and acetyl compounds attached, Glu (85\%), Gal (84\%), and GluAce (83\%) showed greater retention than Ara (74\%). These results were consistent with previous studies reporting anthocyanin hexosides to be more stable than pentosides [14, 28-30]. Additionally, West and Mauer [27] reported that sugar structure, namely glucoside, and acylated derivatives of glucosides (acetyl, malonoyl, and coumaroyl) did not affect degradation of anthocyanins in purified and semi-purified extracts from grape pomace, purple corn, and black rice. 
Our results for glucosides, galactosides and acetylated derivatives of glucosides support their findings, but our results indicate that arabinosides, which were not measured in the study of Mauer and West [27], were more prone to degradation in response to pasteurization than other glycosides. However, in another study investigating anthocyanin losses during blueberry juice processing, anthocyanin losses were reported to be affected more by aglycone structure than by type of sugar moiety attached [10]. Discrepancies among studies may reflect differences in processing steps employed or variation in glycosidase activities of enzyme preparations used for juice processing [31-33].

\section{3. $\mathrm{pH}$, storage temperature and storage time effects on anthocyanins and percent polymeric color of pasteurized blueberry juice}

The concentrations of total anthocyanins and percent polymeric color values of pasteurized blueberry juice as affected by $\mathrm{pH}$, storage temperature and storage time are shown in Fig. 3. Marked losses of total anthocyanins occurred from time 0 (pasteurized juice) to two months of storage in juices that were stored at $25^{\circ} \mathrm{C}$. During this time, juices acidified to $\mathrm{pH} 2.1$ retained higher levels of total anthocyanins $(78 \% ; 84.1 \mathrm{mg} / 100 \mathrm{~mL})$ than both pH $2.5(71 \% ; 71.9 \mathrm{mg} / 100 \mathrm{~mL})$ and control juices $(62 \% ; 62.3 \mathrm{mg} / 100 \mathrm{~mL})($ Std Err Diff =2.36). The initial large loss of anthocyanins was unexpected, but may be the result of heat resistant forms of polyphenol oxidase or peroxidase that were not totally inactivated by the pasteurization step [34], or ascorbic acid catalyzed degradation of anthocyanins [35, 36]. Levels of total anthocyanins continued to decline over 2 to 8 months of storage regardless of storage temperature, but as expected juices stored at $4{ }^{\circ} \mathrm{C}$ retained much higher levels of total anthocyanins than juices stored at $25^{\circ} \mathrm{C}$. Juices stored at $4^{\circ} \mathrm{C}$ had on average $56 \%$ higher levels of total anthocyanins $(98.7 \mathrm{mg} / 100 \mathrm{~mL})$ than juices stored at $25^{\circ} \mathrm{C}(63.3 \mathrm{mg} / 100 \mathrm{~mL})(\mathrm{Std}$ Err Diff $=2.80)$. Retention of total anthocyanins was also influenced by juice $\mathrm{pH}$, with juices acidified to $\mathrm{pH} 2.1(90.5 \mathrm{mg} / 100 \mathrm{~mL})$ having on average $12 \%$ and $26 \%$ higher levels of total anthocyanins than $\mathrm{pH} 2.5(80.5 \mathrm{mg} / 100 \mathrm{~mL})$ and $\mathrm{pH} 2.9(72.1 \mathrm{mg} / 100 \mathrm{~mL})$ juices, respectively (Std Err Diff = 5.86). After 8 months of storage, juices acidified to pH $2.1(94.9 \mathrm{mg} / 100 \mathrm{~mL})$ had 11 and $22 \%$ higher levels of total anthocyanin than $\mathrm{pH} 2.5(85.7 \mathrm{mg} / 100 \mathrm{~mL})$ and 2.9 juices $(78.5 \mathrm{mg} / 100 \mathrm{~mL})$ stored at $4{ }^{\circ} \mathrm{C}$ (Std Err Diff $\left.=2.29\right)$. After eight months of storage at ambient temperature, juices acidified to pH $2.1(62.9 \mathrm{mg} / 100 \mathrm{~mL})$ had $26 \%$ and 59\% higher levels of total anthocyanins than $\mathrm{pH} 2.5(49.7 \mathrm{mg} / 100 \mathrm{~mL})$ and 2.9 juices $(39.7 \mathrm{mg} / 100 \mathrm{~mL})(\operatorname{Std}$ Err Diff $=2.48)$. A reduced model fit for each temperature (with $\mathrm{R}^{2}=0.94$ respectively concludes that in each storage temperature environment there were only the significant main effects of storage duration and $\mathrm{pH}$. The analysis for both room and refrigerated suggests statistically significant retention with each lower $\mathrm{pH}$ level and significant loss of the total anthocyanins with each storage treatment level beyond 4 months. A linear model could capture $98 \%$ of the variability of the total anthocyanins without any significant Lack of Fit. Furthermore, we could conclude from that reduced model that total anthocyanins tend to decline (beyond the first four months) linearly about $4.8(\mathrm{mg} / 100 \mathrm{~mL})$ per month on average independent of temperature and $\mathrm{pH}$ treatments.

The degradation of anthocyanins in juices subjected to long-term storage at ambient temperature in this study are consistent with other studies on berry juices. Control juices ( $\mathrm{pH} 2.9$ ) in this study lost $50 \%$ of total anthocyanins over six months of storage, while non-clarified juices of black raspberries, blueberries and blackberries lost $62 \%$, $68 \%$ and $75 \%$ of total anthocyanins, respectively over the same storage period $[12,13,37]$. Extensive losses of total anthocyanins were also reported for blueberry-aronia juices stored for 207 days in glass (89\% loss), and juice stored for 183 days in cartons ( $92 \%$ loss) [28].

Consistent with loss of total anthocyanins, percent polymeric color values increased over eight months of storage and refrigerated storage ameliorated the increase in percent polymeric color in juices stored at $25^{\circ} \mathrm{C}$ (Fig. 3). Juices stored at $4{ }^{\circ} \mathrm{C}$ had on average $20 \%$ polymeric color, while juices stored at $25^{\circ} \mathrm{C}$ had $33 \%$ polymeric color (Std Err Diff =1.41). Percent polymeric color was also impacted by $\mathrm{pH}$ with juices acidified to $\mathrm{pH} 2.1$ and 2.5 having lower average polymeric color $(24 \%)$ than non-acidified $\mathrm{pH} 2.9$ juices $(31 \%)$ (Std Err Diff $=2.46)$. After 8 months of storage at $4^{\circ} \mathrm{C}, \mathrm{pH} 2.1$ and 2.5 juices had lower polymeric color (20 and $22 \%$ ) than non- 


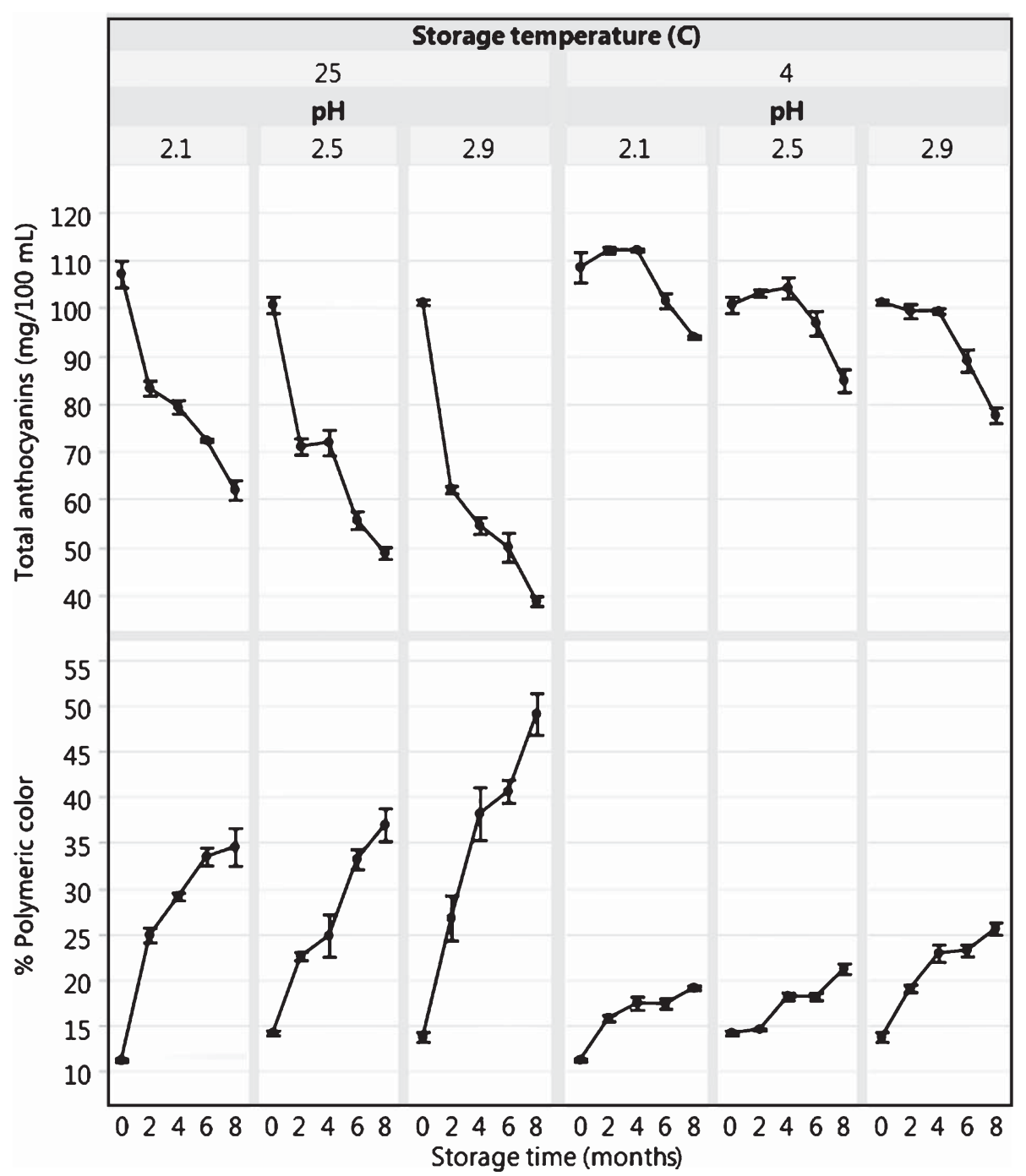

Fig. 3. Total anthocyanin content $(\mathrm{mg} / 100 \mathrm{~mL})$ and percent polymeric color of blueberry juice as affected by $\mathrm{pH}$, storage time and temperature. Bars represent standard error of the mean $(n=3)$.

acidified pH 2.9 juices $(26 \%)$ (Std Err Diff =0.78). A similar trend was observed after 8 months of storage at $25^{\circ} \mathrm{C}$, with and $\mathrm{pH} 2.1$ and 2.5 juices having 35 and $37 \%$ polymeric color compared to $49 \%$ for $\mathrm{pH} 2.9$ juices (Std Err Diff $=2.58$ ). Levels of total anthocyanins and percent polymeric color values over storage showed a significant inverse correlation $\left(\mathrm{r}_{\mathrm{xy}}=0.91\right)$, indicating that the low amount of anthocyanins remaining after 8 months of storage were present to a large degree in polymeric form. All individual anthocyanins showed inverse correlations with polymeric color values with the exception of acetylated derivatives of Dpd, Mvd, and Ptd, which tended to have much lower correlations than all monoglycosides (data not shown). We believe the lower correlation for the acetylated derivatives is due to their instability, especially under acidic conditions. It is possible that anthocyanins react with proanthocyanidins via a direct condensation reaction during storage to form polymeric pigments. However, another possibility is that the concentration of anthocyanin-proanthocyanidin 


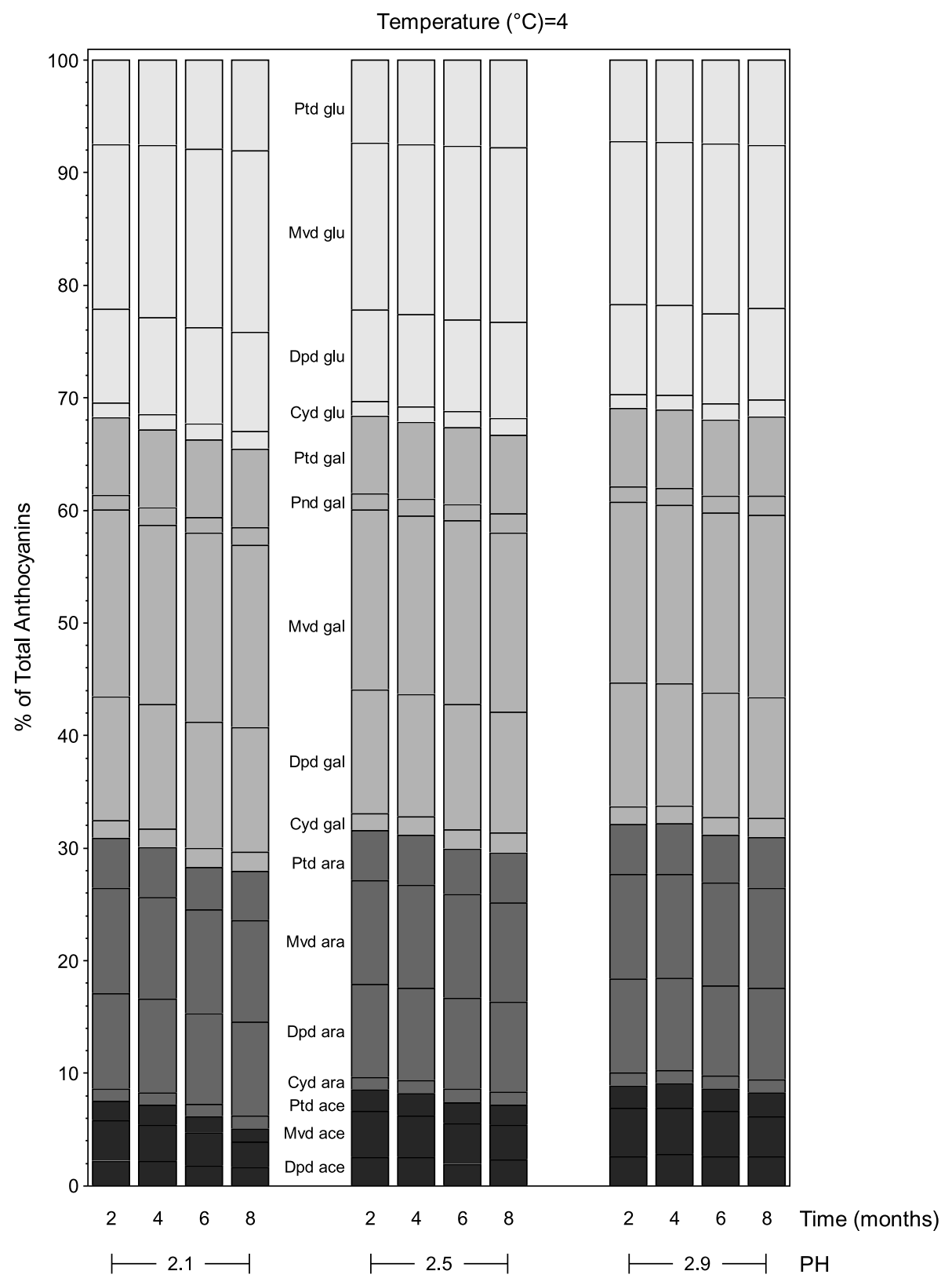

Fig. 4. Anthocyanin composition (\% of total anthocyanins) of blueberry juice over eight months of storage at $4{ }^{\circ} \mathrm{C}$ as affected by $\mathrm{pH}$.

polymers do not change appreciably during storage, but the compounds are much more resistant to degradation than monomeric anthocyanins. This scenario would also result in increased percent polymeric color values over storage. More research is needed to isolate and quantify anthocyanin-proanthocyanidin polymers in order to determine their fate during storage. 


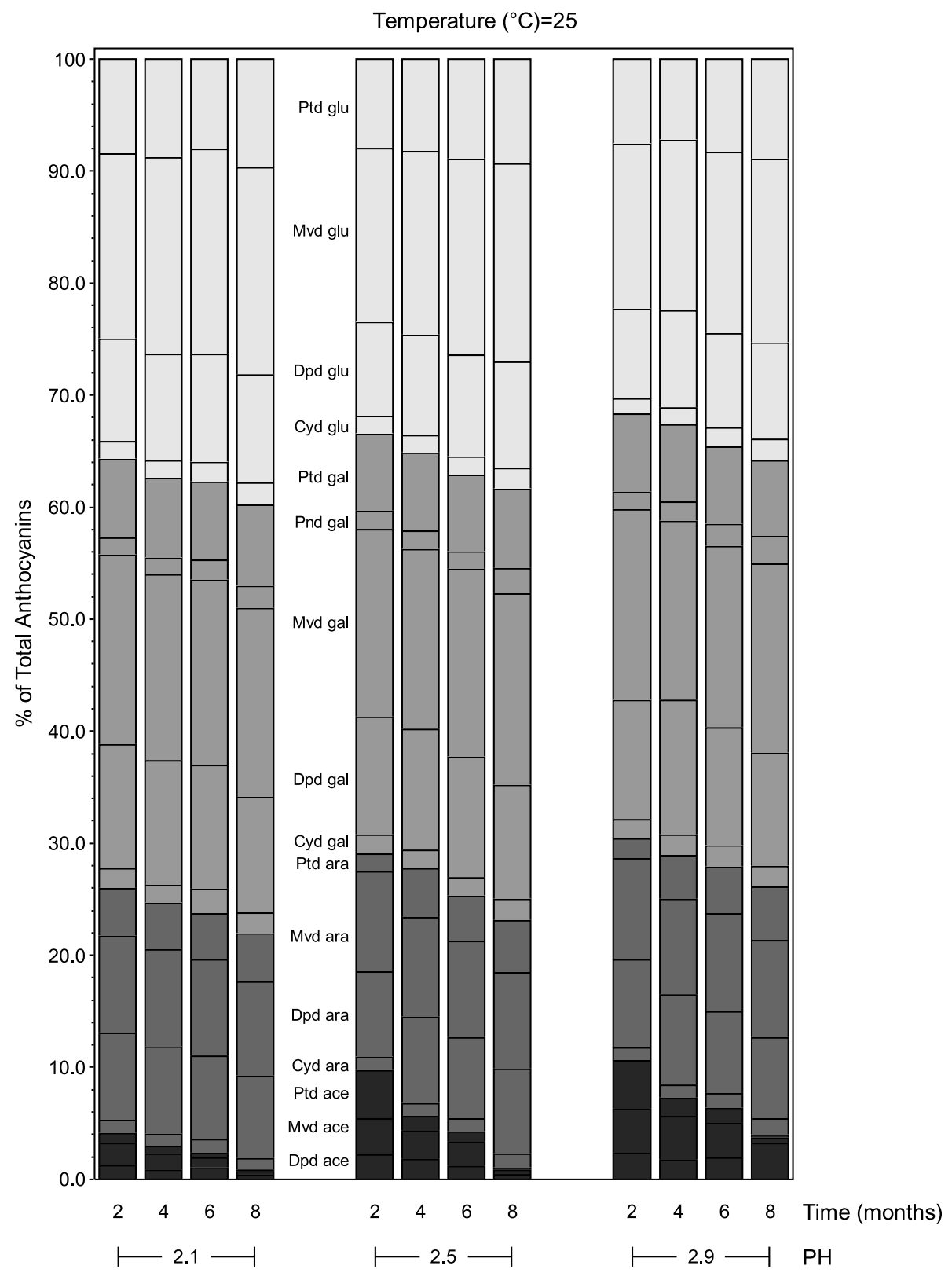

Fig. 5. Anthocyanin composition (\% of total anthocyanins) of blueberry juice over eight months of storage at $25^{\circ} \mathrm{C}$ as affected by $\mathrm{pH}$.

Levels of all individual anthocyanins decreased over eight months of storage, but the losses were affected by storage temperature and $\mathrm{pH}$. Over all storage times, juices stored at $4{ }^{\circ} \mathrm{C}$ had on average $41,56,57,62$ and $32 \%$ higher levels of total Cyd, Mvd, Ptd, Dpd and Pnd derivatives than juices stored at $25^{\circ} \mathrm{C}$. Over all storage times and temperatures, juices acidified to $\mathrm{pH} 2.1$ had on average 8, 13, 12, 9, and 11\% higher levels of total Cyd, Dpd, Mvd, Pnd and Ptd derivatives than juices acidified to $\mathrm{pH}$ 2.5, and 28, 25, 26, 19 and 25\% higher levels of total Cyd, Dpd, Mvd, Pnd and Ptd derivatives than non-acidified juices ( $\mathrm{pH} 2.9$ ). 
Changes in individual anthocyanins expressed as percentage of total anthocyanins are shown in Fig. 4 for refrigerated juices and Fig. 5 for juices stored at $25^{\circ} \mathrm{C}$. In juices stored at $4{ }^{\circ} \mathrm{C}$ (Fig. 4), Ptd 3-glu, Mvd 3-glu, Dpd 3-glu, and Cyd 3-glu accounted for a larger percentage of total anthocyanins over storage at each pH, while Ptd 3-gal, Pnd 3-gal, Mvd 3-gal, Dpd 3-gal, Cyd 3-gal, Ptd 3-gal and Cyd 3-ara changed little and Mvd 3-ara, Dpd 3-ara, Cyd 3-ace-glu, Ptd 3-ace-glu, Mvd 3-ace-glu and Dpd 3-ace-glu decreased. The effect of juice pH on anthocyanin composition was minimal with the exception of acetylated derivatives of anthocyanidins. Levels of Ptd 3-ace-glu, Mvd 3-ace-glu and Dpd 3-ace-glu accounted for a lower percentage of total anthocyanins in juices acidified to $\mathrm{pH} 2.1$ than juices acidified to $\mathrm{pH} 2.5$ or juices with natural $\mathrm{pH}$ of 2.9 . The acetylated anthocyanins were much more stable over storage in juices with natural $\mathrm{pH}$ of 2.9 than both acidified juices.

Similar changes in anthocyanin composition over storage were observed in juices stored at $25^{\circ} \mathrm{C}$ (Fig. 5), with Ptd 3-glu, Mvd 3-glu, Dpd 3-glu, and Cyd 3-glu accounting for a larger percentage of total anthocyanins over storage at each pH, Ptd 3-gal, Pnd 3-gal, Mvd 3-gal, Dpd 3-gal, Cyd 3-gal, Ptd 3-gal, and Cyd 3-ara changing little and Mvd 3-ara, Dpd 3-ara, Cyd 3-ace-glu, Ptd 3-ace-glu, Mvd 3-ace-glu and Dpd 3-ace-glu decreasing. Similar to results obtained with refrigerated juices, the effect of $\mathrm{pH}$ on anthocyanin composition over storage was minimal, with the exception of acetylated derivatives, which accounted for a much lower percentage of total anthocyanins in $\mathrm{pH} 2.1$ juices than both acidified juices.

The instability of acetylated derivatives over storage was surprising since acylated anthocyanins are reported to be much more stable than monomeric anthocyanins as a result of their intra- and intermolecular co-pigmentation properties [38, 39]. However, acylated anthocyanins from purple carrot, red potatoes, red radish, and red cabbage showing greater stability than monomeric anthocyanins typically have one or more aromatic acids such as $p$-coumaric, cinnamic, or ferulic esterified to the 6-OH of the sugar moieties attached at $\mathrm{C} 3$ on the pyrylium ring [39]. Our results indicate that the esterified acetyl moiety is labile to acidic conditions making the acetylated derivatives more prone to degradation during storage of blueberry juice than glycosides. The observed increases in Ptd 3glu, Mvd 3-glu, Dpd 3-glu and Cyd 3-glu as a percentage of total anthocyanins during storage may be due to cleavage of the acetyl moiety from their acetylated counterparts. Further work employing purified compounds is needed to confirm if acetylated derivatives can be converted to monomeric anthocyanins under acidic conditions.

\section{Conclusions}

Acidification of blueberry juice to $\mathrm{pH} 2.1$ ameliorated anthocyanin losses and increase in percent polymeric color observed in control ( $\mathrm{pH} 2.9$ ) and juices acidified to $\mathrm{pH} 2.5$ following pasteurization. Anthocyanin arabinosides were more susceptible to degradation in response to pasteurization than glucosides, galactosides and acetylated derivatives. Levels of total anthocyanins declined markedly over 8 months of storage, but acidification of juices to 2.1 and refrigerated storage were both effective in mitigating anthocyanin losses. After 8 months of storage, juice acidified to $\mathrm{pH} 2.1$ had 11 and $22 \%$ higher levels of total anthocyanins than $\mathrm{pH} 2.5$ and control juices stored at $4{ }^{\circ} \mathrm{C}$, and $26 \%$ and 59\% higher levels of total anthocyanins than $\mathrm{pH} 2.5$ and control juices stored at $25^{\circ} \mathrm{C}$. Acetylated derivatives were more prone to losses during storage than monoglycosides, especially in acidified juices.

\section{References}

[1] Prior RL, Lazarus SA, Cao G, Muccitelli H, Hammerstone JF. Identification of procyanidins and anthocyanins in blueberries and cranberries (Vaccinium spp.) using high-performance liquid chromatography/mass spectrometry. J Agric Food Chem. 2001;49:127076. 
[2] Cho MJ, Howard LR, Prior RL, Clark JR. Flavonoid glycosides and antioxidant capacity of various blackberry, blueberry, and red grape genotypes determined by high-performance liquid chromatography/mass spectrometry. J Sci Food Agric. 2004;84:1771-82.

[3] Kalt K, McDonald JE. Chemical composition of lowbush blueberry cultivars. J Amer Soc Hort Sci. 1996;121:142-46.

[4] Moyer RA, Hummer KE, Finn CE, Frei B, Wrolstad RE. Anthocyanins, phenolics, and antioxidant capacity in diverse small fruits: Vaccinium, Rubus and Ribes. J Agric Food Chem. 2002;50:519-25.

[5] Pellegrini N, Serafini M, Colombi B, Del Rio D, Salvatore S, Bianchi M, Brighenti F. Total antioxidant capacity of plant foods, beverages and oils consumed in Italy assessed by three different in vitro assays. J Nutr. 2003;133:2812-29.

[6] Wu X, Beecher GR, Holden JM, Haytowitz DB, Gebhardt SE, Prior RL Lipophilic and hydrophilic antioxidant capacities of common foods in the United States. J Agric Food Chem. 2004;52:4026-37.

[7] Duffy KB, Spangler EL, Devan BD, Guo Z, Bowker JL, Janas AM, Hagepanos A, Minor RK, DeCabo R, Mouton PR, Shukitt-Hale B, Joseph JA, Ingram DK. A blueberry-enriched diet provides cellular protection against oxidative stress and reduces a kainite-induced learning impairment in rats. Neurobiol Aging. 2008;29:1680-89.

[8] Han X, Shen T, Lou H. Dietary polyphenols and their biological significance. Int J Mol Sci. 2007;8:950-88.

[9] Quideau S, Deffieux D, Douat-Casassus CD, Pouysegu, L. Plant polyphenols: Chemical properties, biological activities, and synthesis. Angewandte Chemie Int Ed. 2011;50:586-621.

[10] Skrede G, Wrolstad RE, Durst RW. Changes in anthocyanins and polyphenolics during juice processing of highbush blueberries (Vaccinium corymbosum L.) J Food Sci. 2000;65:357-64.

[11] Lee J, Durst RW, Wrolstad RE. Impact of juice processing on blueberry anthocyanins and polyphenolics: Comparison of two pretreatments. J Food Sci. 2002;67:1660-67.

[12] Brownmiller C, Howard LR, Prior RL. Processing and storage effects on monomeric anthocyanins, percent polymeric color, and antioxidant capacity of processed blueberry products. J Food Sci. 2008;73:H72-79.

[13] Hager TJ, Howard LR, Prior RL. Processing and storage effects on monomeric anthocyanins, percent polymeric color, and antioxidant capacity of processed blackberry products. J Agric Food Chem. 2008;56:689-5.

[14] Howard LR, Castrodale C, Brownmiller C, Mauromoustakos A. Jam processing and storage effects on blueberry polyphenolics and antioxidant capacity. J Agric Food Chem. 2010;58:4022-29.

[15] Rossi M, Giussani E, Morelli R, Lo Scalzo R, Nani RC, Torreggiani D. Effect of fruit blanching on phenolics and radical scavenging activity of highbush blueberry juice. Food Res Int. 2003;36:999-1005.

[16] Brambilla A, Lo Scalzo R, Bertolo G, Torreggiani D. Steam-blanched highbush blueberry (Vaccinium corymbosum L.) juice: Phenolic profile and antioxidant capacity in relation to cultivar selection. J Agric Food Chem. 2008;56:2643-48.

[17] Sablani SS, Andrews PK, Davies NM, Walters T, Saez H, Syamaladevi RM, Mohekar PR. Effect of thermal treatments on phytochemicals in conventionally and organically grown berries. J Sci Food Agric. 2010;90:769-79.

[18] Simard RE, Bourzeix M, Heredia N. Factors influencing color degradation in blueberry juice. Lebensm Wissen Technol. 1982;15:17780 .

[19] Kalt W, McDonald JE, Donner H. Anthocyanins, phenolics, and antioxidant capacity of processed lowbush blueberry products. J Food Sci. 2000;65:390-93.

[20] Srivastava A, Akoh CC, Yi W, Fischer J, Krewer, G. Effect of storage conditions on the biological activity of phenolic compounds of blueberry packed in glass bottles. J Agric Food Chem. 2007;55:2705-13.

[21] Reque PM, Steffens RS, Jablonski A, Flores SH, Rios ADO, Jong EVD. Cold storage of blueberry (Vaccinium spp.) fruits and juice: Anthocyanin stability and antioxidant activity. J Food Comp Anal. 2014;33:111-16.

[22] Brouillard, R. Flavonoids and flower colour. In The Flavonoids. Advances in Research Since 1980, ed. J.B. Harborne 1988, Chapman and Hall, London, UK.

[23] Fossen T, Cabrita L, Andersen OM. Colour and stability of pure anthocyanins influenced by pH including the alkaline region. Food Chem. 1988;63:435-40.

[24] Giusti MM, Wrolstad RE. Characterization and measurement of anthocyanins with UV-visible spectroscopy, In Current Protocols in Food Analytical Chemistry, Wrolstad RE., Ed.; John Wiley \& Sons: New York, NY, 2001; pp. F1.2.1-F1.2.13.

[25] Kalt W, McDonald JE, Ricker RD, Lu X. Anthocyanin content and profile within and among blueberry species. Can J Plant Sci. 1990;79:617-23.

[26] Torksangerpoll K, Andersen OM. Colour stability of anthocyanins in aqueous solutions at various pH values. Food Chem. 2005;89:42740.

[27] West ME, Mauer LJ. Color and chemical stability of a variety of anthocyanins and ascorbic acid in solution and powder forms. J Agric Food Chem. 2013;61:4169-79.

[28] Troŝt K, Golic-Wondra M, Proŝek M, Milivojevič, L. Anthocyanin degradation of blueberry-aronia nectar in glass compared with carton during storage. J Food Sci. 2008;73:S405-11. 
[29] Ichiyanagi T, Oikawa K, Tateyama C, Konishi T. Acid mediated hydrolysis of blueberry anthocyanins. Chem Pharm Bull. 2001;49:11423.

[30] Howard LR, Brownmiller C, Prior RL, Mauromoustakos A. Improved stability of chokeberry juice anthocyanins by beta cyclodextrin addition and refrigeration. J Agric Food Chem. 2013;61:693-99.

[31] Wightman JD, Wrolstad RE. Anthocyanin analysis as a measure of glycosidase activity in enzymes for juice processing. J Food Sci. 1995;60:862-67.

[32] Buchert J, Koponen JM, Suutarinen M, Mustranta A, Lille M, Torronen R, Poutanen K, Effect of enzyme-aided pressing on anthocyanin yield and profiles in bilberry and blackcurrent juices. J Sci Food Agric. 2005;85:2548-56.

[33] Puupponen-Pimia R, Nohynek L, Ammann S, Oksman-Caldentey KM, Buchert J. Enzyme-assisted processing increases antimicrobial and antioxidant activity of bilberry. J Agric Food Chem. 2008;56:681-88.

[34] Terefe NS, Yang YH, Knoerzer K, Buckow R, Versteeg C. High pressure and thermal inactivation kinetics of polyphenol oxidase and peroxidase in strawberry puree. Innov Food Sci Emerg Technol. 2010;11:52-60.

[35] Poei-Langston MS, Wrolstad RE. Color degradation in ascorbic acid-anthocyanin-flavanol model system. J Food Sci. 1981;46:1218-22.

[36] Pacheco-Palenica LA, Hawken P, Talcott ST. Phytochemical, antioxidant and pigment stability of acai (Euterpe oleracea Mart.) as affected by clarification, ascorbic acid fortification and storage. Food Res Int. 2007;40:620-28.

[37] Hager A, Howard LR, Prior RL, Brownmiller C. Processing and storage effects on monomeric anthocyanins, percent polymeric color, and antioxidant capacity of processed black raspberry products. J Agric Food Chem. 2008;73:H134-40.

[38] Malien-Aubert C, Dangles O, Amoit MJ. Color stability of commercial anthocyanin-based extracts in relation to the phenolic composition. Protective effects by intra- and intermolecular copigmentation. J Agric Food Chem. 2001;49:170-76.

[39] Giusti MM, Wrolstad RE. Acylated anthocyanins from edible sources and their applications in food systems. Biochem Eng J. 2003;14:217-25. 